\title{
Endoscopic Submucosal Dissection for Superficial Esophageal Neoplasm: A Growing Body of Evidence
}

\author{
Eun Jeong Gong and Hwoon-Yong Jung \\ Department of Gastroenterology, Asan Medical Center, University of Ulsan College of Medicine, Seoul, Korea
}

See "Clinical outcomes of endoscopic submucosal dissection for superficial esophageal squamous neoplasms" by Jung Soo Park, Young Hoon Youn, Jae Jun Park, et al., on page 168-175.

Recent advances in endoscopic techniques, including magnifying endoscopy and image-enhanced endoscopy, have increased the detection rate of early-stage esophageal squamous cell neoplasm (ESCN). Treatment options for superficial ESCN have expanded, with endoscopic resection considered the standard treatment. Several studies have reported favorable clinical outcomes of endoscopic resection for superficial ESCN that are comparable to those of esophagectomy, with minimal invasiveness. ${ }^{1-4}$

Endoscopic treatment for ESCN includes endoscopic mucosal resection (EMR) and endoscopic submucosal dissection (ESD), with ESD has enabled en bloc resection for large tumors. ESD for esophageal neoplasm is technically difficult and requires advanced endoscopic skills because of the narrow space and peristalsis of the esophagus. This technical difficulty may result in incomplete tumor resection, increasing the likelihood of recurrence. Different risk factors associated with local recurrence have been reported, including the size of lesion, piecemeal resection, and EMR as compared with ESD. ${ }^{5}$ Although ESD enabled to overcome these factors, effort

Received: March 3, 2016 Revised: March 5, 2016

Accepted: March 6, 2016

Correspondence: Hwoon-Yong Jung,

Department of Gastroenterology, Asan Digestive Disease Research Institute, Asan Medical Center, University of Ulsan College of Medicine, 88 Olympic-ro 43-gil, Songpa-gu, Seoul 05505, Korea

Tel: +82-2-3010-3197, Fax: +82-2-476-0824, E-mail: hyjung@amc.seoul.kr

(cc) This is an Open Access article distributed under the terms of the Creative Commons Attribution Non-Commercial License (http://creativecommons.org/ licenses/by-nc/3.0) which permits unrestricted non-commercial use, distribution, and reproduction in any medium, provided the original work is properly cited. should be made to achieve en bloc curative resection of esophageal neoplasm.

In this issue of Clinical Endoscopy, Park et al. ${ }^{6}$ reported the clinical outcomes of ESD for superficial ESCN. ESD was performed in 32 patients with 36 lesions, and the en bloc resection and R0 resection rates were $97.2 \%$ (35/36) and 91.7\% (33/36), respectively. There was no case of local recurrence or distant recurrence during a median follow-up period of 27 months after curative resection. These results are consistent with those of previous reports that showed favorable clinical outcomes after ESD. ${ }^{1,3,4}$

ESD is currently indicated for lesions that do not exceed the mucosal layer (T1a), particularly for those confined to the lamina propria mucosa, because of their negligible risk of lymph node metastasis. ${ }^{7,8}$ Although some reports showed favorable outcomes, ESD for tumors invading the muscularis mucosa or the submucosa (T1b) remains controversial and is considered relative to the indications. ${ }^{9,10}$ There have been attempts to expand the indications of ESD for superficial ESCN. However, the long-term risk of metastasis after endoscopic resection was associated with the tumor invasion depth, and the 5 -year overall survival rates of patients with tumors invading the muscularis mucosa or submucosa were significantly lower than those of patients with tumors confined to the lamina propria mucosa in a previous report. ${ }^{1}$ More evidence regarding the risk of lymph node and distant metastasis in patients with tumors invading the muscularis mucosa or submucosa is warranted to justify the use of ESD for these lesions.

In the present study, 33.3\% (12/36) of enrolled cases did not 
satisfy the current indication for ESD, with the presence of tumors invading the muscularis mucosa or submucosa. Most of these patients might have seemed suitable for undergoing ESD; nevertheless, they were cases of non-curative resection. Indeed, various imaging techniques, including magnifying endoscopy with narrow-band imaging, endoscopic ultrasonography, and computed tomography scanning, were used before ESD to determine the tumor invasion depth and lymph node metastasis. However, the differentiation of tumors invading the muscularis mucosa or submucosa from those confined to the lamina propria mucosa remains challenging, and the difficulty in predicting invasion depth may be attributable to these results. The authors suggested that the macroscopic appearance of a non-flat type tumor may be one of the factors that can predict submucosal invasion. However, the exact estimation of tumor invasion depth before endoscopic resection remains limited. A thorough evaluation based on various imaging modalities and accurate determination of whether a patient is an appropriate candidate for undergoing ESD is essential to improve the curative resection rate.

Complications associated with ESD for ESCN include bleeding, perforation, and stricture. Bleeding during the procedure can be successfully treated with coagulation forceps or hemoclips. Delayed bleeding may require emergency endoscopy and can be managed endoscopically. Perforation during ESD can be treated by endoscopic closure with endoclips followed by conservative medical treatment. Stricture is a well-known complication in patients who undergo ESD for circumferential tumors in the esophagus, and the risk of stricture was reportedly as high as $17 \%{ }^{11}$ Several risk factors for stricture formation were reported, including a mucosal defect occupying more than three-fourths of the circumference, longitudinal mucosal defects $>30 \mathrm{~mm}$, and EMR compared to ESD. ${ }^{12}$ Endoscopic balloon dilatation is effective in controlling post-ESD stricture, and various innovative prevention methods including intralesional injection or oral adminitration of steroid and endoscopic transplantation of cell sheets can be beneficial in case of anticipated risk of stricture formation. ${ }^{11,13,14}$ In the present study, a symptomatic esophageal stricture occurred in five cases (13.9\%) in which the lesions extended to more than three-fourths of the esophageal circumference. These patients were treated with multiple sessions of endoscopic balloon dilatation with or without local steroid injections and temporal stenting. Since post-ESD stricture and the resultant dysphagia decrease patients' quality of life, it should be considered that resection size and circumferential extension are associated with esophageal stricture risk.

Additional treatment after endoscopic resection should be based on the risks of lymph node and distant metastasis as well as patients' medical fitness. Surgery has been a mainstay of the definite treatment for non-metastatic esophageal cancer and non-curative resection after endoscopic resection. However, perioperative mortality and morbidity remain higher than other procedures despite advances in surgical techniques. In this study, five of six patients with non-curative resection after ESD underwent additional treatment, including concurrent chemoradiotherapy, radiotherapy, and surgery. The remaining patient with submucosal invasion refused additional treatment. During the follow-up period, all patients but one had no local or distant recurrence. Considering that esophageal cancer is diagnosed in old age in most patients and additional treatments such as surgery may affect patients' quality of life, the decision to perform additional treatment should be made carefully. Concurrent chemoradiotherapy or radiotherapy may be an effective and relatively safe alternative treatment modality compared to surgery, and watchful waiting may be an option for selected patients.

This study has several limitations. First, considering its retrospective and single-center design, selection bias cannot be excluded. Second, although the clinical outcomes were excellent, the number of patients enrolled in this study is very small. Third, the indication for ESD was not clearly documented. The presumed indication at the time of choosing ESD as well as final histopathologic criteria should be listed. Despite these limitations, this study adds to a growing body of evidence supporting the current indication of ESD for superficial ESCN.

In summary, ESD for superficial ESCN showed favorable clinical outcomes, suggesting that it may be an effective and safe treatment strategy. Procedure-related complications such as esophageal stricture may occur, in particular, lesions involving over three-fourths of the esophageal circumference. In addition to the technical aspect of ESD, more detailed studies with long-term follow-up data are needed to determine the feasibility of ESD for tumors invading the muscularis mucosa or submucosa.

Conflicts of Interest

The authors have no financial conflicts of interest.

\section{REFERENCES}

1. Yamashina T, Ishihara R, Nagai K, et al. Long-term outcome and metastatic risk after endoscopic resection of superficial esophageal squamous cell carcinoma. Am J Gastroenterol 2013;108:544-551.

2. Shimizu Y, Takahashi M, Yoshida T, et al. Endoscopic resection (endoscopic mucosal resection/endoscopic submucosal dissection) for superficial esophageal squamous cell carcinoma: current status of various techniques. Dig Endosc 2013;25 Suppl 1:13-19.

3. Kim DH, Jung HY, Gong EJ, et al. Endoscopic and oncologic outcomes of endoscopic resection for superficial esophageal neoplasm. Gut Liver 2015;9:470-477. 
4. Joo DC, Kim GH, Park DY, Jhi JH, Song GA. Long-term outcome after endoscopic submucosal dissection in patients with superficial esophageal squamous cell carcinoma: a single-center study. Gut Liver 2014;8:612-618.

5. Ishihara $\mathrm{R}$, Iishi $\mathrm{H}$, Takeuchi $\mathrm{Y}$, et al. Local recurrence of large squamous-cell carcinoma of the esophagus after endoscopic resection. Gastrointest Endosc 2008;67:799-804.

6. Park JS, Youn YH, Park JJ, Kim JH, Park H. Clinical outcomes of endoscopic submucosal dissection for superficial esophageal squamous neoplasms. Clin Endosc 2016;49:168-175.

7. Kuwano H, Nishimura Y, Oyama T, et al. Guidelines for diagnosis and treatment of carcinoma of the esophagus April 2012 edited by the Japan Esophageal Society. Esophagus 2015;12:1-30.

8. Cho JW, Choi SC, Jang JY, et al. Lymph node metastases in esophageal carcinoma: an endoscopist's view. Clin Endosc 2014;47:523-529.

9. Katada C, Muto M, Momma K, et al. Clinical outcome after endoscopic mucosal resection for esophageal squamous cell carcinoma invading the muscularis mucosae: a multicenter retrospective cohort study. Endoscopy 2007;39:779-783.

10. Higuchi K, Tanabe S, Koizumi W, et al. Expansion of the indications for endoscopic mucosal resection in patients with superficial esophageal carcinoma. Endoscopy 2007;39:36-40.

11. Kim GH, Jee SR, Jang JY, et al. Stricture occurring after endoscopic submucosal dissection for esophageal and gastric tumors. Clin Endosc 2014;47:516-522.

12. Ezoe Y, Muto M, Horimatsu T, et al. Efficacy of preventive endoscopic balloon dilation for esophageal stricture after endoscopic resection. J Clin Gastroenterol 2011;45:222-227.

13. Ohki T, Yamato M, Ota M, et al. Prevention of esophageal stricture after endoscopic submucosal dissection using tissue-engineered cell sheets. Gastroenterology 2012;143:582-588.

14. Lee WJ, Jung HY, Kim DH, et al. Intralesional steroid injection to prevent stricture after near-circumferential endosopic submucosal dissection for superficial esophageal cancer. Clin Endosc 2013;46:643-646. 